\title{
THE EFFECTS OF ARTIFICIAL CRAB SPIDERS (THOMISIDAE: Misumenops spp.) ON Piper POLLINATOR BEHAVIOUR IN COSTA RICA: DIFFERENCES BETWEEN INSECT ORDERS
}

\author{
Meghan Doris Kelley ${ }^{1,2 *}$, Markus Creachbaum ${ }^{1}$, Amanda Mineo ${ }^{1}$ \& John Wilson Finger Jr. ${ }^{2}$
}

\author{
${ }^{1}$ John Carroll University, University Heights, Department of Biology. Ohio, OH, 44118,USA. \\ ${ }^{2}$ Auburn University, Department of Biological Sciences. Auburn, AL, 36849,USA. \\ E-mails: mdk0014@auburn.edu, mcreachbaum15@jcu.edu, amanda.n.mineo@gmail.com,jwf0016@auburn.edu
}

\begin{abstract}
Communication drives ecosystem interactions, including the visual signals of plants used to attract pollinators. However, the effectiveness of flower color in attracting pollinators increases dishonest signalling by pollinator predators exploiting floral inflorescences as hunting niches. Negative pollinator associations with spiders on flowers may cause avoidance of specific plants, thus reducing plant fitness from decreased pollination, but this remains understudied. In this study, we used clay models to simulate crab spiders (Misumenops spp.) on Piper plants in a paired design (spider vs. no spider) on the same plant to further investigate the role of pollinator predators on pollinator behaviour. Using this design, we compared avoidance and visitation of Piper plants, identified pollinators to order (and to insect, if possible, such as the case with bees, wasps, and ants in Hymenoptera), and observed individual insect behaviour towards spiders. Piper pollinators were more likely to be aware of spider treatments $v s$. controls and were also 5.01 times as likely to avoid spider treatments $(p<0.001)$. Visitation on controls was also higher, but this was not found to be significant $(p=0.800)$. Overall, nine orders of pollinators were observed visiting Piper plants, with Hymenopterans, Dipterans, and Coleopterans found to be the dominant orders observed with differences in visitation and avoidance, using Poisson distributions in generalized linear model analyses. This study provides a framework for investigating non-consumptive effects of predators on plant fitness.
\end{abstract}

Keywords: clay models; food webs; insect-plant interactions; plant fitness.

Flowers utilize bright colours to attract visuallyoriented insect pollinators through communicating food rich reward signals that culminate in increased pollination and plant fitness (Tepedino 1979, Suttle 2003, Brechbühl et al. 2010). However, the visual signal of plant colour can be intercepted by other organisms as well, resulting in a top-down cascade, in which a pollinator-predator can indirectly reduce plant fitness (Letourneau \& Dyer 1998, Schmitz et al. 2000, Suttle 2003, Muñoz and Arroyo 2004, Romero et al. 2011). While signal interceptors, such as plant-predators, can physically damage a plant directly through folivory (Marquis 1992, Schmitz et al. 2000), plant fitness may also be impacted by indirect, or non-consumptive, costs as well (Letourneau \& Dyer 1998, Gastreich 1999, Gonçalves-Souza et al. 2008). Just as plant colour may serve as an effective attractant for certain groups of pollinators, these signals may also attract pollinator predators, like spiders (Heiling et al. 2003).

Crab spiders (Thomisidae) are ambush predators of floral bloom pollinators, utilizing crypsis in two distinct ways (Bhaskara et al. 2009, Llandres et al. 2013). Firstly, crab spiders exhibit a number of colourful phenotypes (e.g., brown, green, yellow, and white), which are preferentially used to match plant colour (Chittka 2001, Heiling \& Herberstein 2004, Heiling et al. 2005, Bhaskara et al. 2009, Llandres et al. 2013, Anderson \& Dodson 2015). Secondly, crab spiders may use UV-reflectance/contrast for camouflage or to attract UV-visually oriented pollinators, such as bees or butterflies (Chittka 2001, Heiling \& Herberstein 2004, Thery et al. 2005). While this utilization of crypsis may increase predation success, insect pollinators may also learn to avoid plants or areas inhabited by spiders through their recognition of certain shapes (e.g., rounded abdomen) or structural features (e.g., forelimbs) of spider predators through the development of spider-specific search images (Heiling \& Herberstein 2004, Gonçalves-Souza et al. 2008, Ings et al. 2012). Indeed, because crab spiders 
initiate attacks with their forelimbs, spider recognition and avoidance of forelimbs would appear to be an essential learned association necessary for pollinator survival that would likely cause avoidance of a certain area or plant (Dukas \& Morse 2003). Therefore, failed spider attacks may represent a true measure of pollinator risk assessment and learning.

In this study, crab spider clay models (modelled after Misumenops species) were used to assess predator avoidance (i.e., adaptive learning) and plant visitation behaviour in insect pollinators of Piper plants (pepper plants; Piperaceae) in Costa Rica, namely Piper cenocladum. While previous studies have also used similar models to assess adaptive learning in plant pollinators (e.g., Gonçalves-Souza et al. 2008, Ings et al. 2012, Wang et al. 2013), to our knowledge, no study has investigated the effects of spider models on Piper insect pollinator behaviour at both the hierarchical level of order and at the individual level for Hymenopterans. Using a paired design of control Piper flowers lacking spider models and experimental Piper flowers containing spider models, we hypothesized that both avoidance and visitation would differ between the two experimental treatments, with increased avoidance and decreased visitation in experimental flowers relative to control flowers. We further hypothesized that visitation and avoidance would differ between insect orders, since pollinators may behave differently in response to spider predators (Dukas \& Morse 2003, Gonçalves-Souza et al. 2008). In addition, we hypothesized that visitation would be highest in the morning as has been shown previously (Fleming 1985, Kikuchi et al. 2007).

This study was conducted in the lowland tropical forests of Costa Rica, near La Selva Biological Station (LSBS; $10^{\circ} 25^{\prime} 53.14^{\prime \prime} \mathrm{N}$; 840'10.51"W) from 2-8 March 2013. The study site was approximately 100 meters in elevation and receives about $3962 \mathrm{~mm}$ of rainfall annually (Letourneau \& Dyer 1998). Although March is part of the Costa Rican dry season, this study was conducted during an unseasonably wet period, which coincides with the stimulus (i.e., rain) for flowering in tropical Piper plants (Fleming 1985).

There are more than 90 species of Piper L. in Costa Rica, with plants often inhabiting riparian zones of tropical lowland forests or along forest edges
(Burger 1971, Fleming 1985). Piper species are tall shrub-like plants, commencing flower production between 1-15 m in height (Letourneau \& Dyer 1998). They are characterized by possessing white, spikelike inflorescences that have very small flowers in which the anther and stigma are in close proximity, ensuring an act of visitation is also likely an act of pollination (Fleming 1985).

Artificial spider clay models were handmade with white, non-toxic Sculpey clay (Polyform Products Company, Elk Grove Village, IL, USA; reflectance spectra $300-700 \mathrm{~nm}$ ) in a similar fashion to artificial spider models in other studies (e.g., Gonçalves-Souza et al. 2008). Briefly, model body weight $(<1 \mathrm{~g})$ and body $(.1 .5 \mathrm{~cm})$, forelimb $(.3 \mathrm{~cm}$ total), and leg length (. $2 \mathrm{~cm}$ total; Figure 1) were standardized proportionally to resemble Misumenops spp. (Thomisidae) (Gonçalves-Souza et al. 2008), notably M. pallens (Keyserling; body length . $1 \mathrm{~cm}$ ), which is found throughout central and South America (World Spider Catalog 2017). Two bent paper clips were inserted into the model to resemble raptorial forelimbs. Since the objective of this study was to understand if visually-oriented pollinators recognized spider models, olfactory cues of models were not considered. However, models were placed outside for approximately 1 month in an attempt to account for clay scent.

Fifty-seven Piper (identified to genus) plants were used in this study. All plants were . $1 \mathrm{~m}$ in height, spaced $>1 \mathrm{~m}$ apart, similar in colour (reflectance spectra 300-400 nm), in bloom (i.e., capable of attracting pollinators), and randomly distributed across various microhabitats along edges of designated trails at LSBS. Microhabitats included areas close to water or buildings near the station, plantation regions, or secondary growth forest. At 30 minute intervals 2 times/day (morning and afternoon), three individual experimenters individually observed a flowering Piper plant. Each plant $(\mathrm{N}=57)$, used only once, included a pair-wise comparison of a control inflorescence with no-spider model and an experimental inflorescence containing the artificial spider model (placed at start of observation). The two treatment inflorescences were spaced $>30 \mathrm{~cm}$ apart (Gonçalves-Souza et al. 2008), at approximately the same height, and on the 
same plant per trial in order to prevent potential interplant variations that could confound results. Experimenters stood at a distance of approximately 1 $\mathrm{m}$ (from the plant) to observe pollinators either avoiding or visiting the two inflorescent treatments. A priori, avoidance behaviour was defined as the approach of a pollinator for $\$ 3$ seconds near an inflorescence without walking or landing on the inflorescence, whereas visitation was defined as any walking or landing on one of the two inflorescences for a timed period of \$ 3 seconds (Gonçalves-Souza et al. 2008). In the event of avoidance or visitation, insect pollinators were identified to order using general characteristics (see Gillot 2005).

All statistical analyses were performed in $\mathrm{R}$ (Version i386 3.2.2., 2015). Number of visitations and avoidances by pollinators, respectively, along with total number of pollinators (i.e., avoidances + visitations) served as response variables. Since data for visitation, avoidance, and total number of pollinators were counts, general linear models with Poisson distributions were conducted for all analyses. Model treatment (spider $v s$. no spider) served as the main fixed effect in analysis. In avoidance and visitation analyses, to account for variation, observer bias, plant number (based on observer), and location served as random effects, whereas time (of day) served as a random effect in avoidance-visitation analyses and as an independent variable in analyses for examing time of day effects on the number of pollinator visitors. Nesting of appropriate variables (i.e., blocking larger factors, such as time of day, within smaller factors, such as treatment) was also used in broader analyses, as well as the observance of possible interactions between treatments and insects on numbers of avoidances and visitations.

All odds ratios ( $\beta$ ) and confidence limits (CLs) were created using coefficients of variation, taking appropriate values from analysis to the exponential power. Because count data analysed via Poisson distributions are expected to be non-normal, CLs ( $\beta \pm$ 2 xstandard error) with $95 \%$ confidence to account for the expected asymmetry in the results were used rather than confidence intervals. To demonstrate the effect of spider models on pollinator visitation and avoidance, $\beta$ s: $95 \%$ CLs are provided below. A $\beta>1$ indicates that an outcome is more likely to occur, whereas a $\beta<1$ indicates an outcome is less likely to occur. A 5\% significance level was chosen to evaluate fixed effects.

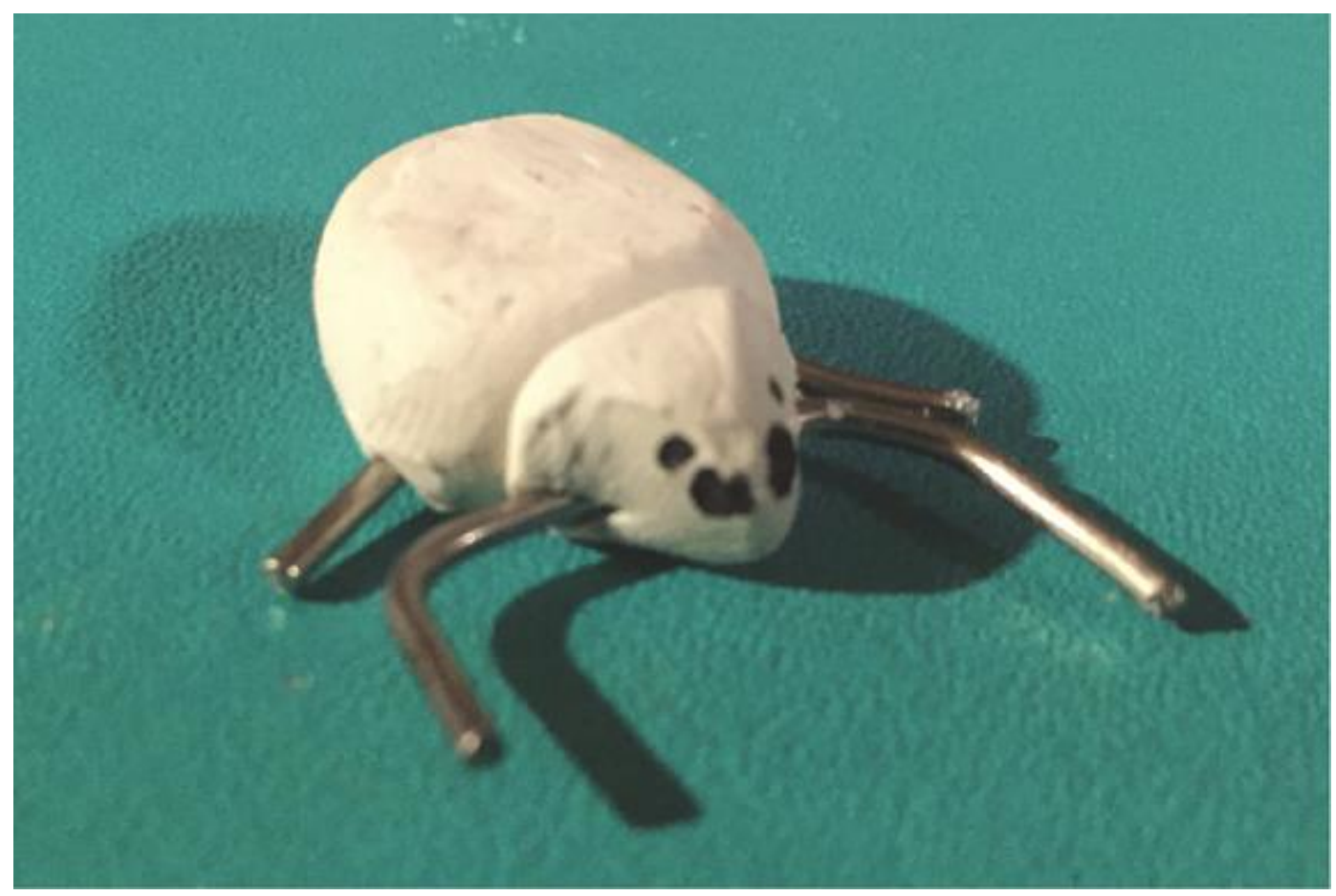

Figure 1. Representative model spider made of white clay. 
Overall, there were a total of 345 pollinators (268 avoidances and 77 visitations) observed near Piper inflorescences in this study, distributed among nine insect orders (Table 1). Pollinators significantly avoided spider inflorescences more often than control inflorescences (Odds ratio: confidence limit, 5.01: 3.606.98; $\mathrm{p}<0.001$ ) and visited control inflorescences more often (0.944:0.59-1.50; $\mathrm{p}=0.800$ ) than spider treated ones, supporting our hypothesis.

Hymenopterans were the only insect order that were significantly more likely to both avoid (2.31: 1.194.50; $\mathrm{p}=0.012)$ and visit (2.20: 0.98-4.91; $\mathrm{p}=0.050)$ spider models more often than controls, contrary to our original hypothesis. To further investigate this, we compared behaviors between ants, bees, and wasps (Figure 2). Bees significantly avoided (2.26: 1.51-3.0; $\mathrm{p}=0.030$ ) both treatments more often than ants, but visited spider models less than ants (0.12: 1.92-2.16; $\mathrm{p}<0.001)$. Because ants live on Piper plants and gain food from extra-floral nectaries, they may exhibit increased territoriality or aggression to perceived threats to their home or food source (Letourneau 1998), accounting for their increased visitation. In fact, we observed ants both attacking spider models and exhibiting behavioural displacement (see Gastreich 1999). Bees, however, likely avoided spiders due to the chance of being predated upon.

Both Dipterans (7.77: 4.83-12.50; $\mathrm{p}$ 0.001) and Coleopterans (3.12: 1.45-6.71; $\mathrm{p}=0.003$ ) significantly avoided spider models more often than controls. Since crab spiders are well-documented predators of Dipterans, and Coleopterans (Jennings 1974, Heiling \& Herberstein 2004, Brechbühl et al. 2010), experienced individuals from these prey groups may possess spider search images and consequently, avoided models. Even though all other insect orders avoided spider treatments more than controls (Figure 2; Table 1), this was not significant. Lepidopterans were previously shown to be a dominant leaf forager of Piper plants at La Selva (see Marquis 1992), but only 7 individuals were observed in this study. Since Lepidopterans rely heavily upon olfaction, especially for foraging and mating (e.g., Yoshida et al. 2015), sensory aversion to models may account for the low numbers observed. Ants may have also influenced Lepidopteran behaviour through the emission of olfactory-alarm cues to suspected predators (i.e., the spider model; Attygale \& Morgan 1984).

Due to other studies illustrating pollinator proclivity for early morning Piper pollination in the tropics (Fleming 1985, Kikuchi et al. 2007), we hypothesized that pollinators would be most active during the morning. In contrast, however, there were significantly (1.37: 1.10-1.71; $\mathrm{p}=0.005$ ) more pollinators observed in the afternoon than in the morning (Table 1). Peak pollination (mostly by Dipterans) was observed between 1500-1600 hours. Interestingly though, pollinators avoided Piper treatments more $(1.40: 1.09-1.81 ; \mathrm{p}=0.007)$ in the afternoon than in the morning.

This study coincided with unseasonably wet weather. Therefore, it is possible that pollinator behaviour was affected by precipitation. Rain can affect photoperiod, olfactory cue transmission, and UV reflectance (see Bowen \& Janzen 2005), all of which could influence pollinator behaviour and perception of

Table 1. Taxonomical avoidance and visitation (Spider vs. No spider) by Piper pollinators at different times of the day.

\begin{tabular}{|c|c|c|c|c|c|c|c|}
\hline \multirow{2}{*}{$\begin{array}{l}\text { Pollinator } \\
\text { Order }\end{array}$} & \multicolumn{2}{|c|}{ Spider Treatment } & \multicolumn{2}{|c|}{ No Spider Treatment } & \multirow{2}{*}{$\begin{array}{c}\text { Total } \\
\text { Pollinators }\end{array}$} & \multirow{2}{*}{$\begin{array}{c}\text { Morning } \\
\text { Pollinators }\end{array}$} & \multirow{2}{*}{$\begin{array}{l}\text { Afternoon } \\
\text { Pollinators }\end{array}$} \\
\hline & Avoidances & Visitations & Avoidances & Visitations & & & \\
\hline Diptera & 155 & 9 & 20 & 14 & 198 & 71 & 127 \\
\hline Hymenoptera & 28 & 21 & 10 & 9 & 68 & 32 & 36 \\
\hline Coleoptera & 28 & 4 & 9 & 9 & 50 & 24 & 26 \\
\hline Lepidoptera & 6 & 0 & 1 & 0 & 7 & 2 & 5 \\
\hline Hemiptera & 6 & 1 & 0 & 5 & 12 & 2 & 10 \\
\hline Araneae & 4 & 2 & 0 & 0 & 6 & 2 & 4 \\
\hline Orthoptera & 1 & 0 & 0 & 1 & 2 & 1 & 1 \\
\hline Phasmida & 0 & 0 & 0 & 1 & 1 & 0 & 1 \\
\hline Chilopoda & 0 & 0 & 0 & 1 & 1 & 0 & 1 \\
\hline Total & 228 & 37 & 40 & 40 & 345 & 134 & 211 \\
\hline
\end{tabular}




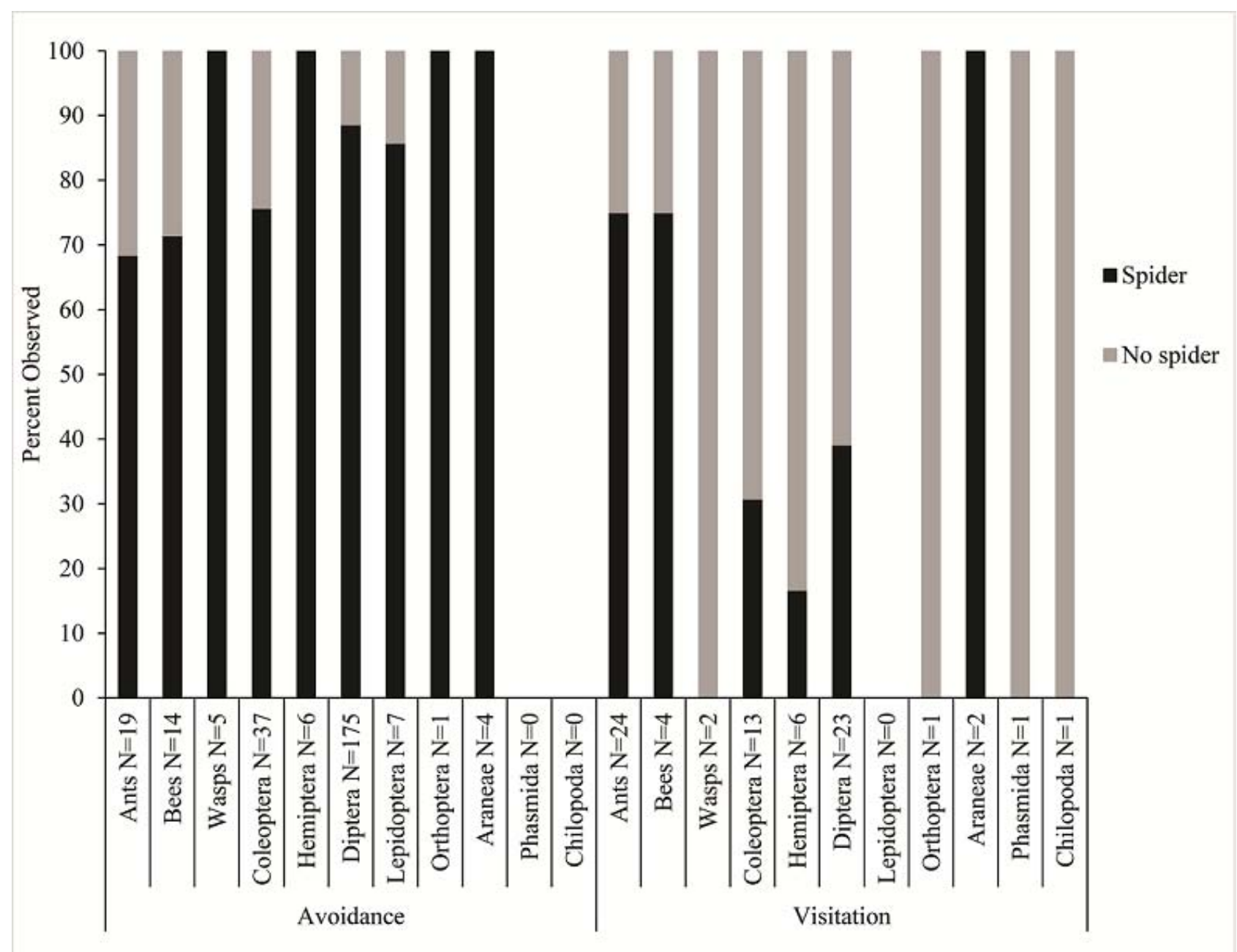

Figure 2. Ratios of avoidance and visitation among the nine observed pollinator orders organized by treatment (spider vs. no spider). Sample sizes (N; i.e., the total number of avoidances of visitations) are provided for each pollinator. Note that no values are provided for avoidance of Phasmida and Chilopoda, along with Lepidoptera visitation, due to no representative individuals observed. Solid bars indicate $100 \%$ visitation or avoidance due to one particular treatment.

spider predators. Additionally, rain may have indirectly affected insect behaviour by affecting the plants themselves. Since rain can cause reversals in Piper phenology (see Stiles 1977), this may have induced unseasonal flowering of certain Piper plant species in the study area. The unseasonably wet weather observed during the study period may represent an obvious confounder of our results, which necessitates further exploration.

In conclusion, we used spider models to investigate Piperacae pollinator behaviour. To our knowledge, this is one of the first studies to investigate, in an entirely open field study, how different orders of arthropod pollinators of Piper plants may be influenced by spider predators. Our results suggest that pollinators were more likely to avoid and less likely to visit spider models, indicating that spiders may influence pollinator behavior. Future studies further investigating the effects of pollinator predators on plant fitness are necessary.

\section{ACKNOWLEDGEMENTS}

We would like to thank the Organization for Tropical Studies, La Selva Biological Station (LSBS), and the Costa Rican government for allowing us to conduct this study. We would also like to thank Ralph Saporito for help with experimental design. Christopher Sheil and Andy Jones helped locate Piper plants at LSBS. MDK was funded by the Biology Department at John Carroll University. 


\section{REFERENCES}

Anderson, A. G., \& Dodson, G. N. 2015. Colour change ability and its effect on prey capture success in female Misumenoides formosipes crab spiders. Ecological Entomology, 40(2), 106-113.

Attygale, A. B., \& Morgan, D. 1984. Chemicals from the glands of ants. Chemical Society Reviews, 13(3), 245-278.

Bhaskara, R. M., Brijesh, C. M., Ahmed, S., \& Borges, R. M. 2009. Perception of ultraviolet light by crab spiders and it role in selection of hunting sites. Journal of Comparative Physiology, 195(4), 409-417.

Bowen, K. D., \& Janzen, F. J. 2005. Rainfall and depredation of nests of the Painted Turtle, Chrysemys picta. Journal of Herpetology, 39(4), 649-652.

Brechbuhl, R., Kropf, C., \& Bacher, S. 2010. Impact of flowerdwelling crab spiders on plant-pollinator mutualisms. Basic and Applied Ecology, 11(1), 76-82.

Burger, W. C. 1971. Piperaceae. Flora Costaricensis. Fieldiana Botany, 35, 5-218.

Chitka, L. 2001. Camouflage of predatory crab spiders on flowers and the colour perception of bees (Aranida: Thimisidae/ Hymenoptera: Apidae). Entomolgia Generalis, 25(3), 181-187.

Dukas, R., \& Morse, D. H. 2003. Crab spiders affect flower visitation by bees. Oikos, 101(1), 157-163.

Fleming, T. H. 1985. Coexistence of five sympatric Piper (Piperaceae) species in a tropical dry forest. Ecology, 66(3), 688-700.

Gastreich, K. R. 1999. Trait-mediated indirect effects of a Theridiid spider on an ant-plant mutualism. Ecology, 80(3), 1066-1070.

Gillot, C. 2005. Entomology. $3^{\text {rd }}$ ed. Dordrecht, Netherlands: Springer: p. 832.

Goncalves-Souza, T., Omena, P. M., Souza, J. C., \& Romero, G. Q. 2008. Trait-mediated effects on flowers: artificial spiders deceive pollinators and decrease plant fitness. Ecology, 89(9), 2407-2413.

Heiling, A. M., Herberstein, M. E., \& Chitka, L. 2003. Pollinator attraction: crab-spiders manipulate flower signals. Nature, 421(6921), 334.

Heiling, A. M., \& Herberstein, M. E. 2004. Predator-prey coevolution: Australian native bees avoid their spider predators. Proceedings for the Royal Society of London, 271, 196-198.

Heiling, A. M., Chitka, L., Cheng, K., \& Herberstein, M. E. 2005. Colouration in crab spiders: substrate choice and prey attraction. The Journal of Experimental Biology, 208(10), 1785-1792.

Ings, T. C., Wang, M. Y., \& Chittka, L. 2012. Colour-independent shape recognition of cryptic predators by bumblebees. Behavioral Ecology and Sociobiology, 66(3), 487-496.
Jennings, D. T. 1974. Crab spiders (Araneae: Thomisidae) preying on scarab beetles (Coleoptera: Scarabaeidae). The Coleopterists Bulletin, 28(1), 41-43.

Kikuchi, D. W., Lasso, E., Dalling, J. W., \& Nur, N. 2007. Pollinators and pollen dispersal of Piper dilatatum (Piperaceae) on Barro Colorodo Island, Panama. Journal of Tropical Ecology, 23(5), 603-606.

Letourneau, D. K. 1998. Ants, stem-borers, and fungal pathogens: experimental tests of a fitness advantage in Piper ant-plants. Ecology, 79(2), 593-603.

Letourneau, D. K. \& Dyer, L. A. 1998. Density patterns of Piper ant-plants and associated arthropods: top-predator trophic cascades in a terrestrial ecosystem? Biotropica, 30(2), 162-169.

Llandres, A. L., Figon, F., Christides, J. P., Mandon, N., \& Casas J. 2013. Environmental and hormonal factors controlling reversible colour change in crab spiders. The Journal of Experimental Biology, 216(20), 3886-3895.

Marquis, R. J. 1992. A bite is a bite is a bite? Constraints on response to folivory in Piper arieianum (Piperaceae). Ecology, 73(1), 143-152.

Munoz, A. A., \& Arroyo, M. T. K.. 2004. Negative impacts of a vertebrate predator on insect pollinator visitation and seed output in Chuquiraga oppositifolia, a high Andean shrub. Oecologia, 138(1), 66-73.

Romero, G. Q., Antiqueira, P. A. P., \& Koricheva, J. 2011. A meta-analysis of predation risk effects on pollinator behavior. PLos One, 6(6), 1-9.

Schmitz, O. J., Hamback, P. A., \& Beckerman, A. P. 2000. Trophic cascades in terrestrial systems: a review of the effects of carnivore removals on plants. The American Naturalist, 155(2), 141-153.

Stiles, F. G. 1977. Coadapted competitors: the flowering seasons of hummingbird-pollinated plants in a tropical forest. Science, 198, 1177-1178.

Suttle, K. B. 2003. Pollinators as mediators of top-down effects on plants. Ecology Letters, 6(8), 688-694.

Tepedino, V. J. 1979. The importance of bees and other insect pollinators in maintaining floral species composition. Great Basin National Memoirs, 3, 39-150.

Thery, M., Debut, M., Gomez, D., \& Casas, J. 2005. Specific color sensitivities of prey and predator explain camouflage in different visual systems. Behavioral Ecology, 16(1), 25-29.

Wang, M.-Y., Ings, T. C., Proulx, M. J., \& Chittka, L. 2013. Can bees simultaneously engage in adaptive foraging behavior and attend to cryptic predators?. Animal Behaviour, 86(4), 859-866.

World Spider Catalog. 2017. World Spider Catalog. Natural History Museum Bern, online at http : //wsc.nmbe.ch, accessed on 22/01/17

Yoshida, M., Itoh, Y., mura, H., Arikawa, K., \& Kinoshita, M. 2015. Plant scents modify innate colour preference in foraging swallowtail butterflies. Biology Letters, 11(7), 1-4. 